\title{
Characteristics of the Shuttle Orbiter Leeside Flow During A Reentry Condition
}

\author{
William L. Kleb * \\ and \\ K. James Weilmuenster ${ }^{\dagger}$ \\ NASA Langley Research Center, Hampton, Virginia, 23665
}

\begin{abstract}
A study of the leeside flow characteristics of the Shuttle Orbiter is presented for a reentry flight condition. The flow is computed using a point-implicit, finite-volume scheme known as the Langley Aerothermodynamic Upwind Relaxation Algorithm (LAURA). LAURA is a second-order accurate, laminar NavierStokes solver, incorporating finite-rate chemistry with a radiative equilibrium wall temperature distribution and finite-rate wall catalysis. The resulting computational solution is analyzed in terms of salient flow features and the surface quantities are compared with flight data.
\end{abstract}

\section{Nomenclature}

\section{Acronyms}

AFRSI Advanced flexible reusable surface insulation

DFI Developmental flight instrumentation

LAURA Langley aerothermodynamic upwind relaxation algorithm

OMS Orbital maneuvering system

PNS Parabolized Navier-Stokes

RCC Reinforced carbon-carbon

RCG Reaction cured gas

RCS Reaction control system

SILTS Shuttle infrared leeside temperature sensing

STEIN Supersonic/hypersonic three-dimensional external inviscid flow

STS Space transportation system

UTC Universal coordinated time

\footnotetext{
${ }^{*}$ Research Engineer, Aerothermodynamics Branch, Space Systems Division.

tSenior Research Engineer, Aerothermodynamics Branch, Space Systems Division, Senior Member AIAA.

Copyright (C)1992 by the American Institute of Aeronautics and Astronautics, Inc. No copyright is asserted in the United States under Title 17, U. S. Code. The U. S. Government has a royalty-free license to exercise all rights under the copyright claimed herein for Governmental purposes. All other rights are reserved by the copyright owner.
}

\author{
Symbols \\ B Semi-span of the wing, $m$ \\ C Local chord of the wing, $m$ \\ $\mathrm{h} \quad$ Altitude, $\mathrm{km}$ \\ L Reference length, $m$ \\ $M_{\infty}$ Mach number \\ $P_{\infty}$ Freestream pressure, $\mathrm{Pa}$ \\ q Heat flux, $\mathrm{W} / \mathrm{cm}^{2}$ \\ $q_{0}$ Reference heat flux, $W / \mathrm{cm}^{2}$ \\ Q Freestream dynamic pressure, $\mathrm{Pa}$ \\ $\mathrm{T}$ Temperature, $\mathrm{K}$ \\ $T_{0} \quad$ Reference temperature, $\mathrm{K}$ \\ $V_{\infty}$ Freestream velocity, $\mathrm{m} / \mathrm{s}$ \\ $\mathrm{X}$ Distance along the longitudinal axis, $\mathrm{m}$ \\ $\mathrm{Y}$ Distance along the pitch axis, $\mathrm{m}$ \\ $\alpha \quad$ Angle of attack, deg \\ $\beta \quad$ Yaw angle, deg \\ $\epsilon \quad$ Emissivity \\ ${ }_{N}$ Atomic nitrogen recombination coefficient \\ , o Atomic oxygen recombination coefficient \\ $\rho_{\infty} \quad$ Freestream density, $\mathrm{kg} / \mathrm{m}^{3}$ \\ $\sigma \quad$ Stefan-Boltzmann constant, $\mathrm{W} / \mathrm{cm}^{2} \mathrm{~K}^{4}$ \\ $\Phi \quad$ Meridional angle, deg
}

\section{Introduction}

During design of lifting-body configurations such as the HL-20, Hermes, Hope II, Buran, etc., the harsh environment during reentry dictates a significant challenge of coping with the associated high heating rates on the windward surfaces. As a result, the windward aerothermodynamic environment has been extensively studied and is fairly well understood. Correspondingly, the thermal protection system (e.g., reusable tiles) can be designed rather efficiently with regard to both safety and weight requirements since the windward environment is reasonably well-defined. The leeside environment, however, has not been studied in great depth. Whereas the extremely high heating values are not commonplace on the leeward side of the vehicle, the flow physics remains 
largely unexplored. Due to this vague knowledge of the leeside flowfield, the design parameters have to be very conservative. This implies a significant weight penalty; and as Bill Lear, of Learjet fame would say, "I'd kill grandma for another pound of weight [reduction]."

The inability of ground test facilities to reproduce the high energy flows present during reentry conditions, coupled with the prohibitive expense of flight tests, leads to the use of analytic methods to describe the flow. Several previous efforts have been made to compute complex vehicle flowfields for reentry speeds for various conditions. ${ }^{1-16}$ Founded on some of the principals of Kutler et al., ${ }^{1}$ the STEIN code of Marconi et al., ${ }^{2}$ was among the first to treat a Shuttle-like configuration using inviscid analysis. Shortly thereafter, Schiff and Steger ${ }^{3}$ introduced the subsonic sublayer approximation for the Parabolized Navier-Stokes (PNS). This enabled stable space-marching of the PNS equations along a body. The PNS work was continued by $\mathrm{Li}^{4,5}$ which consisted of a reentry flow around the a Shuttle-like vehicle, incorporating "real" gas effects. Venkatapthy ${ }^{6}$ used the PNS formulation to compare with wind tunnel data for the Orbiter. This work was followed by Szema et al., ${ }^{10}$ who computed a reentry flight condition for a Shuttlelike configuration. Balakarishnan ${ }^{7}$ presented a zero angle of attack, high Mach number condition, incorporating "real" gas effects. Prabhu et al., ${ }^{8}$ computed a reentry flight condition for the Shuttle Orbiter and compared with flight data. Meanwhile, the more computermemory intensive Euler equation solvers where also being developed and applied to Shuttle-like vehicles at high speeds. ${ }^{9-13}$ More recently, sufficient computational power has enabled the solution of the Full or Thin-layer Navier-Stokes equations over complex reentry vehicles to be computed, including finite-rate chemistry. ${ }^{14-16}$

A limited amount of flight data is available for the Shuttle Orbiter. For the first five flights (STS-15) of the Shuttle Orbiter Columbia, the vehicle was instrumented to measure surface pressures and temperatures. This instrumentation is know as the Developmental Flight Instrumentation (DFI). The surface temperatures and related heating rates are given by Hartung et al. ${ }^{17-19}$ In addition, on subsequent flights of Shuttle Orbiter Columbia, the Shuttle Infrared Leeside Temperature Sensing (SILTS) experiment ${ }^{20}$ provides a map of the surface temperatures over portions of the leeside surface of the vehicle.

This paper intends to make comparisons with available flight data for the Shuttle Orbiter, and to provide some insight of the intricate leeside flow structures during reentry. This flowfield analysis serves to assess the ability of the computational models within LAURA to predict the leeside environment through examining not only the leeside pressures and heating rates, but also

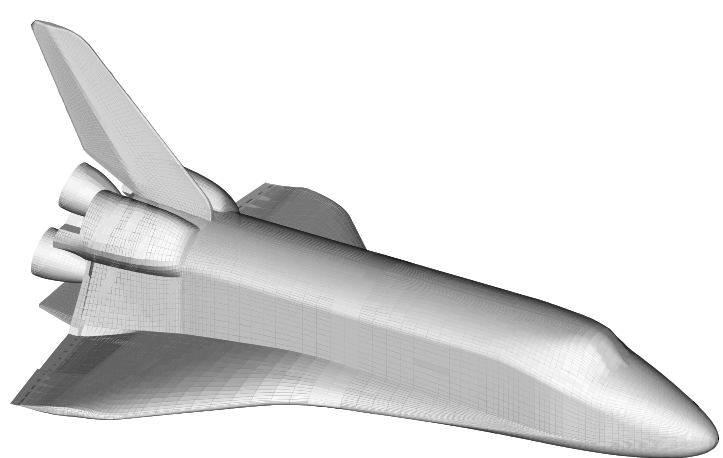

Figure 1: Shuttle Orbiter surface definition.

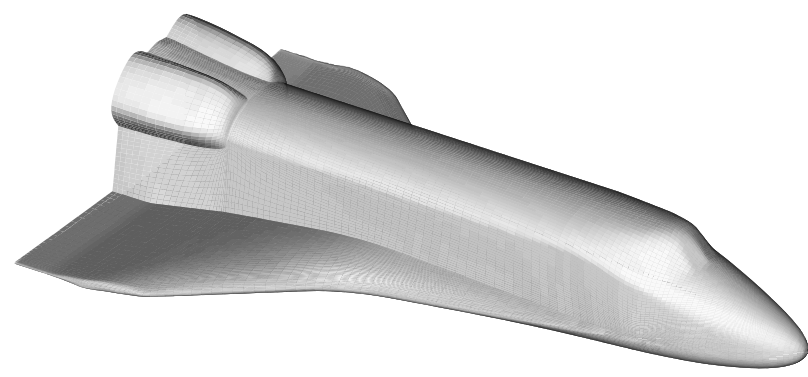

Figure 2: Simplified Shuttle Orbiter surface definition.

through a detailed comparison of the temperature distributions predicted for the leeside of the wing as compared with flight data.

\section{Shuttle Geometry}

The actual Shuttle Orbiter Geometry is shown in Fig. 1. Since the complexity of the aft portion represents a very arduous geometric modeling problem, it was simplified for the purposes of this investigation. The geometrical simplifications consist of the omission of the tail surfaces, body flaps, and continuing the wing's hinge-line edge thickness as a solid surface extending to the outflow plane. Figure 2 shows the simplified geometry. At the high Mach number and high angle of attack flow which is being studied, the pressures and densities are extremely low, and the axial Mach number is predominantly supersonic, so the influence of the simplifications should be localized. 

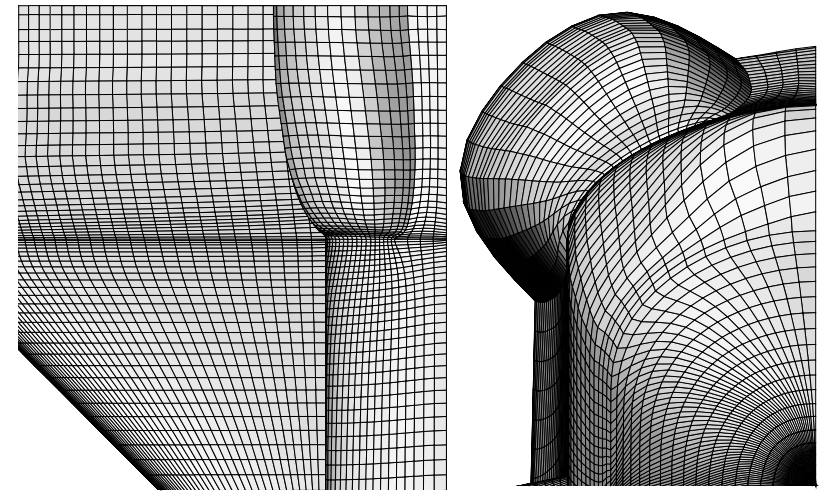

Figure 3: Planform and frontal details of the surface mesh.

The computational mesh was constructed in several phases. First, a surface mesh was generated on the simplified geometry using the GRIDGEN package. ${ }^{21}$ Based on this grid distribution and conservative estimates of the outer boundary location, GRIDGEN was used to generate surface meshes on the remaining boundary faces of the computational domain (the upper and lower symmetry planes, the outflow plane, and the outer boundary). Since all the faces of a "computational cube" had now been defined, the algebriac volume grid generator within GRIDGEN was used to generate the interior points. This algebriac volume grid was then smoothed using the Poisson solver within GRIDGEN, specifying that grid lines should be normal to the body surface and symmetry planes.

The final computational mesh is comprised of just over one million grid points with 121 points distributed stream-wise along the body, 101 points circumferential, and 91 points between the body and just outside the bow shock (i.e., in the uniform, free-stream flow). Figure 3 shows two details (planform and frontal views) of the surface mesh, while Fig. 4 depicts selected planes of the volume mesh (with every other grid line perpendicular to the the body-normal direction removed for visual clarity).

LAURA provides for automatic grid adaptation to the flowfield after an initial solution is generated. This automatic redistribution of points plays the delicate balance of providing proper spacing near the wall to resolve the boundary layer, clustering points in the vicinity of the bow shock, and also providing a minimum number of points outside of the bow shock structure-i.e., that portion of the computational domain where freestream conditions prevail. This form of adaptation not only allows for a highly efficient use of the limited number of

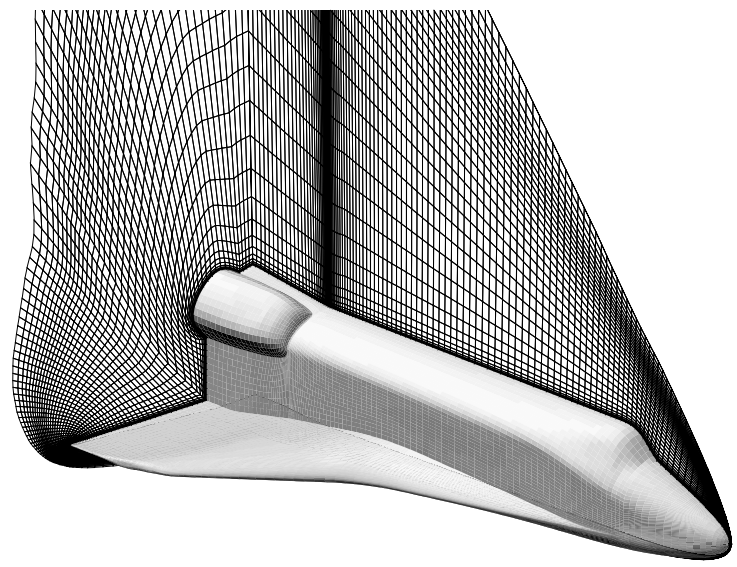

Figure 4: Partial view of volume grid (every other line perpendicular to the body-normal direction omitted for clarity).

grid points available due to computer memory restrictions, but also provides better resolution of the strong bow shock by aligning the computational cells with the shock gradients.

\section{Numerical Method}

The LAURA code is a point-implicit, finite-volume solver based on the upwind-biased flux difference splitting of Roe. ${ }^{22}$ The scheme utilizes Yee's symmetric total variation diminishing discretization ${ }^{23}$ to achieve secondorder spatial accuracy while incorporating Harten's entropy fix. ${ }^{24}$ LAURA is capable of modeling both Euler and laminar Navier-Stokes flow for a host of different air chemistry assumptions: perfect gas, equilibrium, chemical non-equilibrium, and thermochemical non-equilibrium. For this computation, LAURA was primarily run in thin-layer, laminar Navier-Stokes mode with chemical non-equilibrium. Specific details of the basic algorithm can be found in Ref. 25 .

For the altitude and velocity of the flight point considered in this study, it has been shown by Hartung et al. ${ }^{26}$ that the flow over the Shuttle Orbiter is still laminar. The thin-layer assumption (neglecting viscous terms tangential to the body surface) is used for two reasons: (i) reduction of computational resources used (both memory and CPU time) and (ii) as outlined by Baldwin et al., ${ }^{27}$ there is generally not sufficient grid resolution to resolve the streamwise gradients if they were to become significant to the viscous energy momentum balance. The effect of neglecting these terms is discussed in a later section of the paper. 


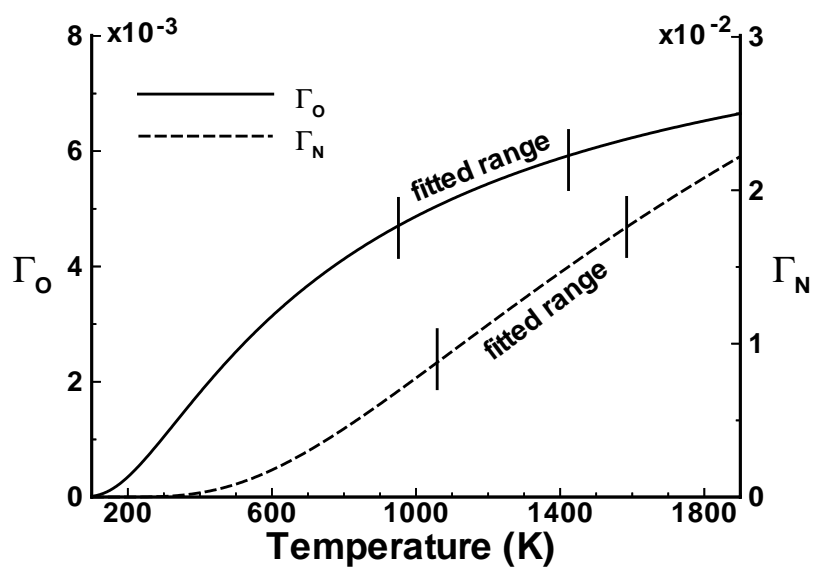

Figure 5: Atomic recombination coefficients for Oxygen and Nitrogen as a function of temperature.

\section{Aerothermodynamic Models}

Some of the major considerations, specific to this flowfield application are presented below. Extensive details of the aerothermodynamic models used in the LAURA code can be found in Ref. 28.

\section{Finite-Rate Chemistry}

The flowfield chemistry is described by the kinetic model of Park $^{29}$ with modifications for the dissociation rates according to Ref. 30. However, two simplifying assumptions were used for this case;

1. Collapsing the two-temperature model into a single temperature.

\section{Using only seven of the proposed eleven species}

The first assumption is physically valid because the post-shock temperatures of this flow are relatively low $(\approx 6500 \mathrm{~K})$, and thus the vibrational, translational, rotational, and electronic energy modes are near equilibrium. The seven species accounted for in this calculation are $\mathrm{O}_{2}, \mathrm{~N}_{2}, \mathrm{O}, \mathrm{N}, \mathrm{NO}, \mathrm{NO}^{+}, e^{-}$. Again, due to the relatively low energy level of the flow, ionization of nitrogen and oxygen would be insignificant if included. (This assumption has been re-affirmed by Hartung through use of an approximate method within Ref. 31.)

\section{Finite-Rate Wall Catalysis}

Zoby $^{32}$ and Scott's ${ }^{33}$ finite-rate wall catalysis curve fits were used to model the wall catalysis of the Shuttle's RCG coated tiles. Figure 5 shows a plot of atomic recombination coefficients with respect to temperature for Oxygen $^{32}$ and Nitrogen. ${ }^{33}$ The validity ranges for both fits are also shown on the plot. Limited data for the lower temperature ranges are available from $\mathrm{Kim}^{34}$ and
Marinelli35,36 which show a trend very similar to that given by the extrapolated curves of Zoby and Scott. The latter method was chosen for the present study to simplify the model and limit the computational expense of computing the wall catalysis.

In addition to the above simplification of the wall catalysis recombination rates, all surfaces of the shuttle (i.e., all types of reusable tile and other surface insulation, including the reinforced carbon-carbon (RCC) found on the leading edge surfaces) were assumed to follow this trend.

\section{Variable Wall Temperature Distribution}

The Stefan-Boltzmann relation was used to develop wall temperature distributions from the computed heating rates. This relation links the emissivity of a surface, $\epsilon$, (the ability to emit radiation compared to a Planck black-body) with the heating rate, $q$, of that surface,

$$
q=\sigma \epsilon T^{4}
$$

where $\sigma$ is the Stefan-Boltzmann constant $(5.67 \times$ $\left.10^{-8} \mathrm{~W} / \mathrm{m}^{2} \mathrm{~K}^{4}\right)$.

The emissivities are a function of temperature and surface type as given by Refs. 17-19. The surface of the Shuttle is composed of many disparate materials, and for this study, surfaces were considered as being either darkor light-colored for determining which set of emissivity functions to use.

Using these relations for emissivities and the StefanBoltzmann relation, a wall temperature, $\mathrm{T}$, at each cell face for the Shuttle surface can be determined from the predicted heating rate, $q$. This iterative process is sustained until neither the predicted heating rates, or the inferred wall temperature distribution are changing significantly $\left(\approx 10^{\circ} \mathrm{K}\right)$.

\section{Flight Data}

As part of the design confirmation procedure for the Shuttle, the Developmental Flight Instrumentation (DFI) was installed on the Orbiter Columbia for the first five flights. Among these instruments were some two hundred thermocouples and pressure transducers distributed over the vehicle surface. The surface temperatures and heating rates for those flights are taken from Refs. 17-19, while the flight surface pressures have been extracted from the DFI database.

The SILTS data represents high-spatial-resolution temperature measurements of the leeside surfaces. ${ }^{20,37}$ An infrared camera was mounted in a pod at the top of the vertical tail, and it alternatively records the thermal environment of the aft portion of the fuselage and the wing. From these images and knowledge of the Orbiter's surface properties, the surface temperatures can 
be determined. For the SILTS flights used in this study, i.e., STS-28 and STS-32, only a small contingent of the original DFI thermocouples on the leeside of the vehicle remained operational. The DFI temperature and heating data for these flights were obtained using the same methods as outlined in Refs. 17-19.

\section{Results and Discussion}

The computational resources required for this study are discussed, followed by a description of the flight conditions used for comparison. Next, a description of the salient features of the leeside flow is given, followed by comparisons of surface quantities: pressures, temperatures, and heating rates.

\section{Computational Resources}

Using the methods described by Weilmuenster et $a l .^{38}$ the Shuttle Orbiter grid was cut into four streamwise sections. The sections varied between 35 and 45 cells in the streamwise direction, and a typical run would require approximately 70 Cray- 2 hours and $100 \mathrm{Mw}$ of memory. This time includes running on the initial grid, aligning the grid, and converging the temperature distribution for each block. After the four sections were converged, all four were put back together into one entire grid and run for an additional 50 Cray- 2 hours. For this latter run, the code was altered so that it could fit within $125 \mathrm{Mw}$ of memory at the expense of efficiency.

\section{Flight Conditions}

A flight trajectory point was chosen so that both DFI data (primarily STS flights 2, 3, and 5) and the SILTS data (STS flights 28 and 32 ) would be available for comparison. The point is fairly early in the trajectory so that the flow over the Shuttle Orbiter is still laminar, but yet low enough $(\approx 70 \mathrm{~km})$ for the continuum assumption to remain plausible (Knudsen numbers $\approx 0.05$ ). The freestream velocities and densities were matched for five flights: STS-2, STS-3, STS-5, STS-28, and STS-32. Table 1 shows the freestream conditions for the matched trajectory point. The freestream conditions of STS-28 were used for the numerical simulation of this study.

\section{Flow Structure}

Figure 6 shows an computer-simulated oil-flow representation of the leeside portion of the Shuttle. The figure clearly depicts many of the separation and reattachment lines present on the vehicle. Starting from the leading edge of the wing and working around to the top portion of the vehicle:

- a region of very low pressure/density due to rapid expansion of the flow around the wing tip (i.e., the wing-tip vortex), and the corresponding cross-flow shock is shown by the abrupt change in flow direction just inboard of the wing tip

- a separation line running just behind the leading edge of the wing strake and continuing through the aft wing section caused by a standing shock triggered by the rapid expansion around the strake leading edge (i.e., the wing strake vortex)

- a re-attachment/shear line located diagonally from the beginning of the wing strake to the leading portion of the Orbital Maneuvering System (OMS) pods

- a stagnation region just ahead of the OMS pods

- a separation line along the upper portion of the body attributed to the standing cross-flow shock which serves to turn the flow parallel to the symmetry plane

- a smaller separation line on the aft portion of the OMS pods due to the cross-flow shock

- a re-circulation region just ahead of the canopy created by the canopy shock

Figure 7 shows particle traces which originate from just ahead of the canopy. Note that the flow from the recirculation region just ahead of the canopy (Fig. 6) leaves the surface and goes up, over the canopy and then spirals back down, wetting the top section of the aft fuselage. The implication of this flow structure will become evident in the discussion of the aft fuselage heating rates.

\section{Surface Pressures}

As shown in Fig. 8, comparisons were made with DFI flight data for the windward and leeward centerline pressures. The windward centerline pressures are in excellent agreement. Towards the aft end of the vehicle (from approximately $\mathrm{X} / \mathrm{L}=0.93$, aft) the computational model does not accurately model the rear portion of the vehicle, and thus the dramatic drop and consequent rise in pressure is not physical. The leeward centerline pressures show show good agreement with the limited amount of flight data.

Figure 9 shows the pressure distribution at the sixty percent semi-span wing station $(2 \mathrm{Y} / \mathrm{B}=0.6)$ as a function of non-dimensionalized chord position $(\mathrm{X} / \mathrm{C})$. The elevon hinge-line occurs at $\mathrm{X} / \mathrm{C}=0.7$ for this semi-span station, and the corresponding deviation can be seen in the predicted lower surface pressures due to the nonphysical modeling of the aft portion of the wing. The leeward pressures compare favorably until approximately the 50 percent chord position. At this point the flight data shows considerably higher pressures. The effect of the elevon deflection might be suspected, but for STS-3 
Table 1: Matched Flight Conditions

\begin{tabular}{ccccccc} 
Quantity & units & STS-2 & STS-3 & STS-5 & STS-28 & STS-32 \\
\hline \hline$U T C$ & sec & 75620 & 56588 & 51120 & 47716 & 33166 \\
$h$ & $\mathrm{~km}$ & 69.2 & 72.9 & 72.4 & 73.2 & 72.8 \\
$M_{\infty}$ & - & 24.3 & 22.2 & 23.6 & 24.3 & 24.4 \\
$V_{\infty}$ & $\mathrm{km} / \mathrm{sec}$ & 6.92 & 7.01 & 6.83 & 7.01 & 7.01 \\
$T_{\infty}$ & $\mathrm{K}$ & 202 & 248 & 209 & 210 & 207 \\
$P_{\infty}$ & $\mathrm{Pa}$ & 3.33 & 3.76 & 3.35 & 3.40 & 3.32 \\
$\rho_{\infty}$ & $\mathrm{kg} / \mathrm{m}^{2} \times 10^{-5}$ & 5.75 & 5.65 & 5.59 & 5.28 & 5.59 \\
$\alpha$ & $\operatorname{deg}$ & 39.4 & 39.5 & 40.3 & 39.4 & 40.0 \\
$\beta$ & $\operatorname{deg}$ & -0.3 & -0.1 & 0.2 & $\mathrm{n} / \mathrm{a}$ & $\mathrm{n} / \mathrm{a}$ \\
bank & $\operatorname{deg}$ & 57 & 64 & -64 & -66 & -71
\end{tabular}

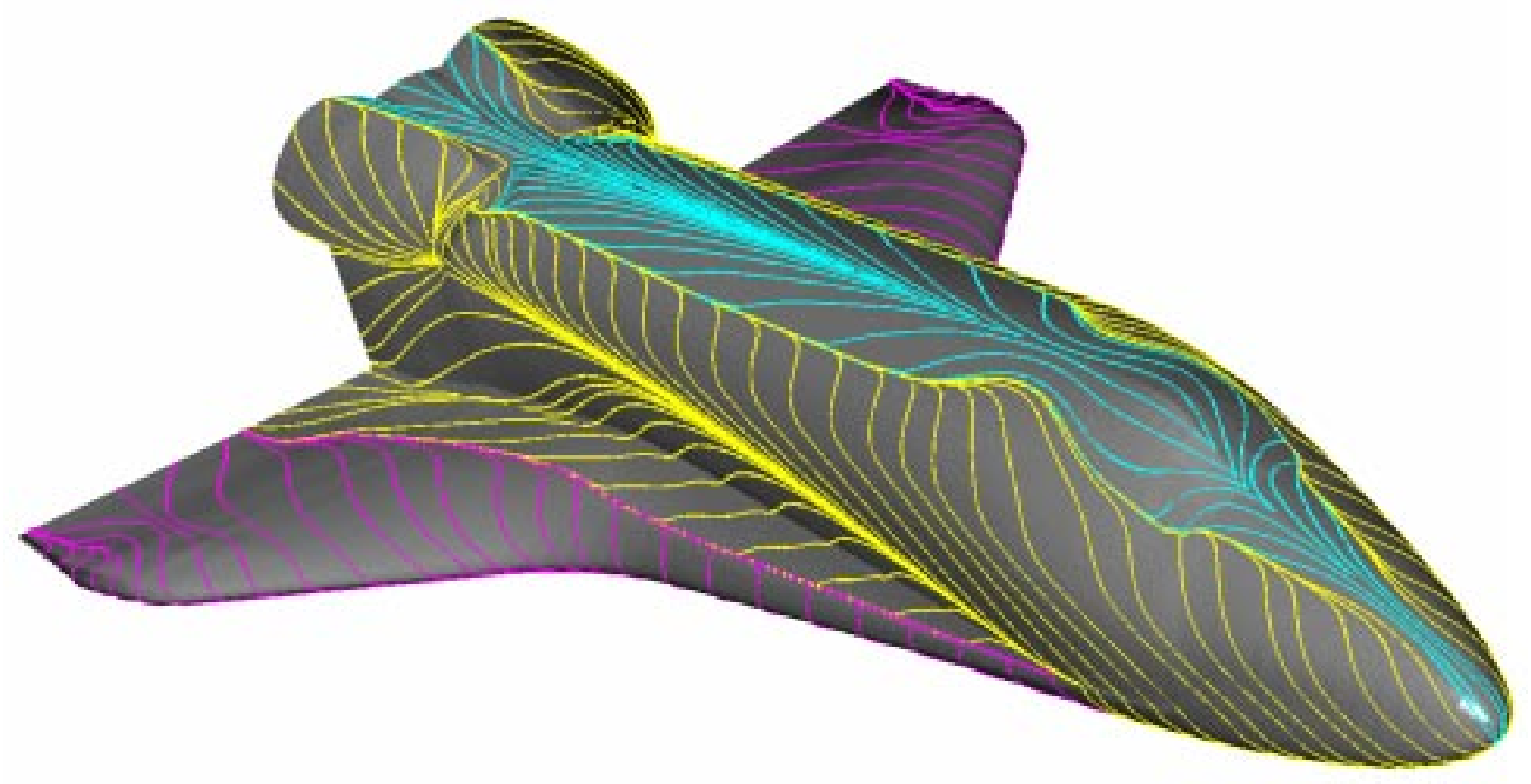

Figure 6: Computer simulated oil-flow on the leeside of the Shuttle Orbiter. 


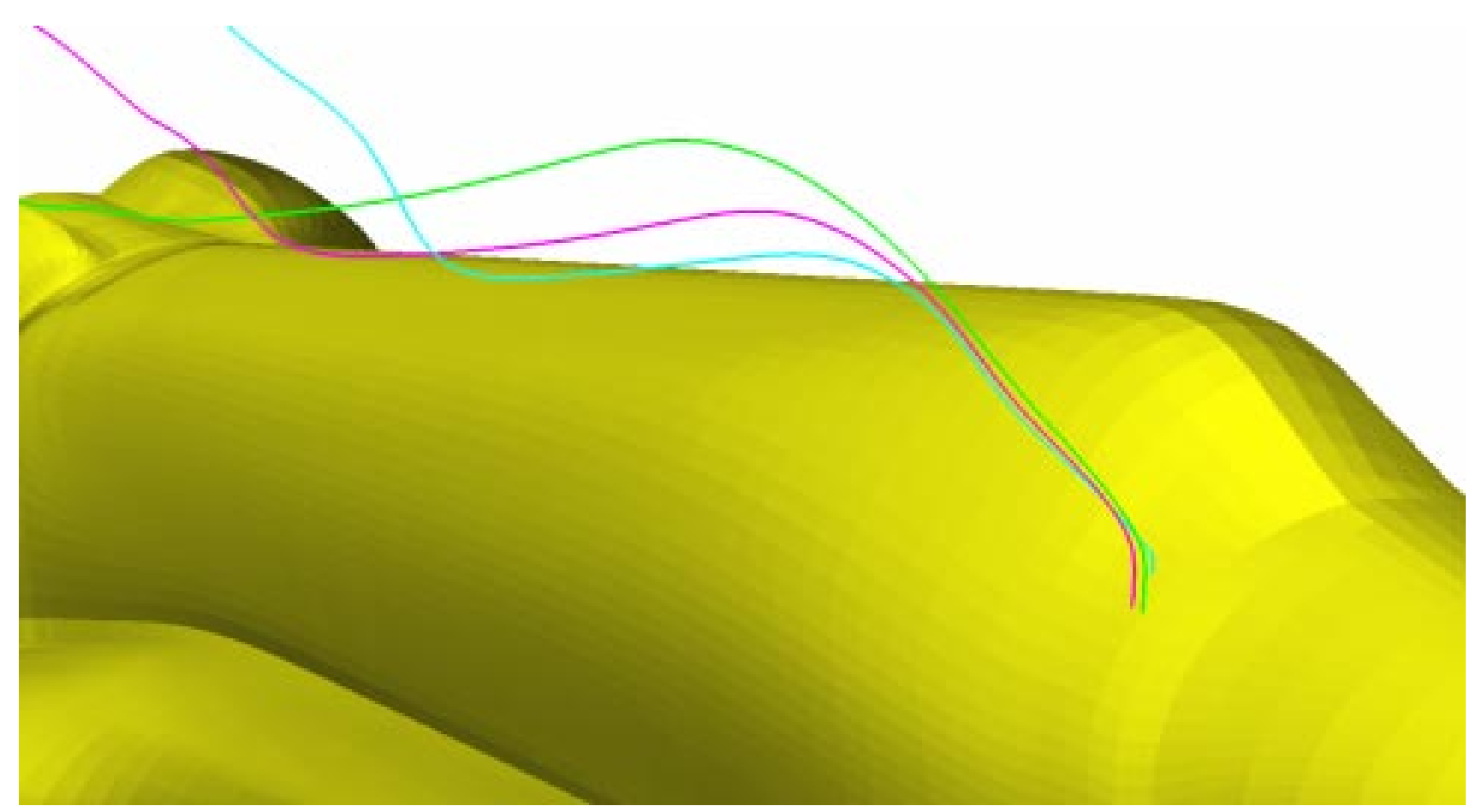

Figure 7: Streamlines originating just ahead of the canopy.

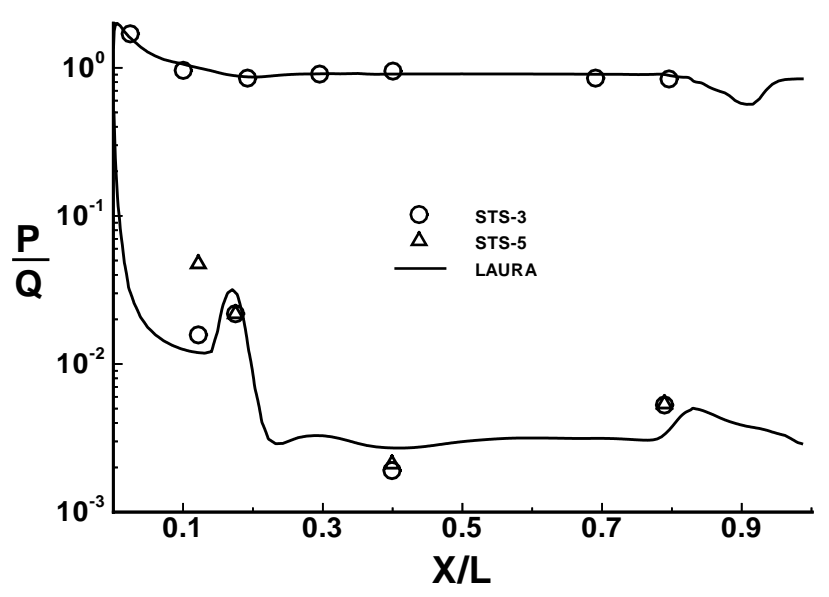

Figure 8: Windward and leeward centerline pressure comparisons.

and STS-5 the elevons were deflected differently (downward $1.7^{\circ}$ and $3.7^{\circ}$, respectively). This discrepancy between predicted and measured pressures is apparently due to bleed-through from the gap between the inboard and outboard elevon. This gap is approximately $18 \mathrm{~cm}$ (7 inches) wide and occurs just inboard of this wing semi-span station. Since this gap was not modeled for the computational solution, the corresponding increase in pressure due to bleed-through from the windside is not present.

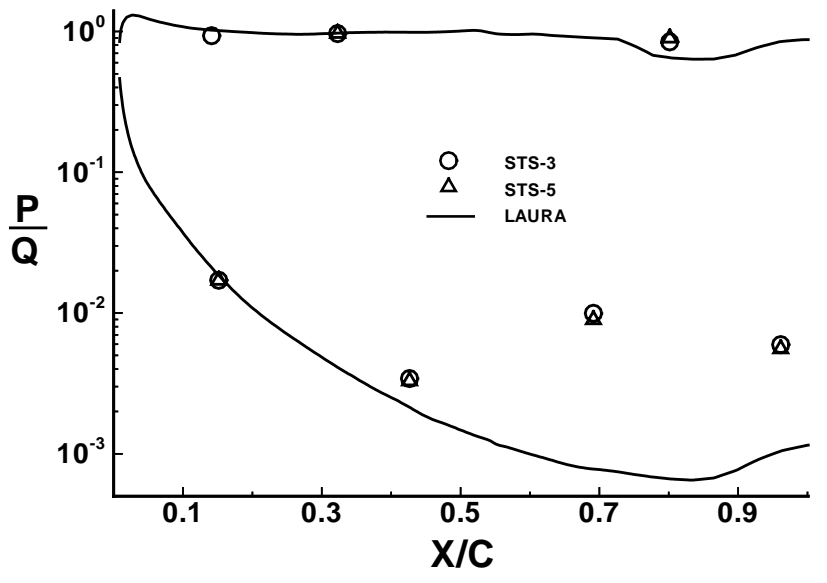

Figure 9: Pressure distribution comparison for wing station $2 \mathrm{Y} / \mathrm{B}=0.60$ as a function of chord.

Figure 10 shows the pressure distribution at the ten percent fuselage station (X/L=0.1). The meridional angle, $\Phi$, is measured from the leeward symmetry plane around to the windward symmetry plane. The figure also includes a half-section depiction of the fuselage at the $\mathrm{X} / \mathrm{L}=0.1$ station. At this location, the predicted and measured pressures agree very well. Again due to sparse pressure data for the leeside, no direct comparison can be made for the top of the fuselage. The trend of the predicted pressures, however, is as expected for a 


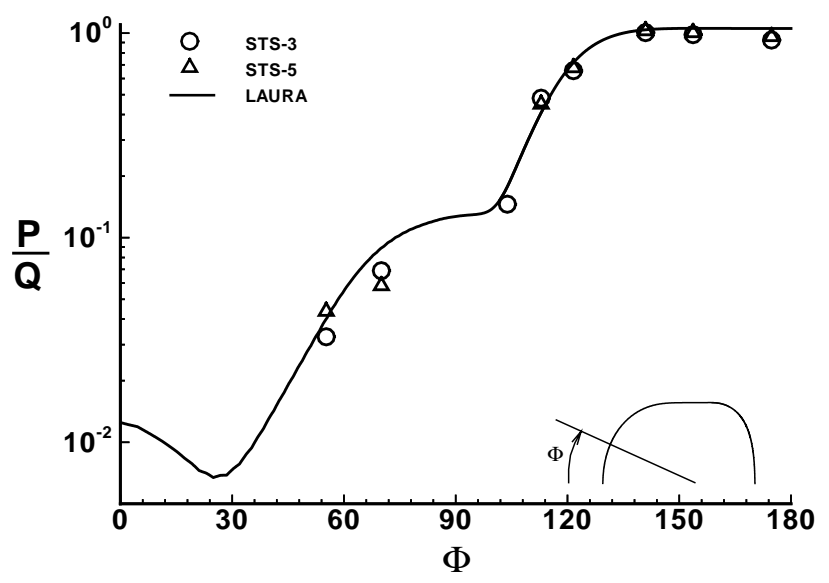

Figure 10: Cross-sectional pressure comparison at fuselage station $\mathrm{X} / \mathrm{L}=0.10$.

blunt-nosed vehicle at moderate angle of attack, showing a rapid expansion and subsequent re-compression while approaching the symmetry plane.

\section{Surface Temperatures}

Figure 11 is a side-by-side comparison of the leeside wall temperature distribution for the aft portion of the Shuttle. The computed results from LAURA are shown on the left-hand side while the measured temperatures from the STS-32 SILTS flight are shown on the right. The SILTS image for STS-28 flight point is nearly identical to STS-32 results, so only the one comparison is presented. Recall that the LAURA temperatures are determined from the radiative equilibrium assumption discussed in a previous section. This equilibrium assumption neglects the effects of the time dependent terms such as conduction.

The figure shows a band of high temperature along the leading edge of the wing as expected. The spotted nature along the forward section of the wing shown in the SILTS image is due to temperature variations across each of the hollow RCC segments which comprise the leading edge. This phenomena is largely due to the reradiation from the windward surface of the hollow RCC leading edge sections through to the leeward surface (see Ref. 37). Also depicted by both methods is a streamwise streak of high temperature at approximately 60 percent of the wing semi-span. This corresponds to the wing-bow shock interaction. In addition, both images show an areas of low temperature located just under the wing tip vortex, below the inboard wing-strake vortex structure, and just ahead of the of the OMS pods. The SILTS image shows a streak of high heating where the windward flow comes through the elevon-elevon gap at the trailing edge of the wing. The computational shuttle model did not model this gap. The rise in heating on the leading edge of the OMS pods is clearly depicted by both methods. Also of interest is that even though the tail was neglected from the computational model of the Shuttle Orbiter, the temperature distributions are remarkably similar on the top of the fuselage, just ahead of where the tail is located.

Figure 12 shows the wing upper surface nondimensionalized temperature distribution as a function of non-dimensionalized chord position for three semispan stations $(2 \mathrm{Y} / \mathrm{B}): 0.40,0.60$, and 0.75 . Each figure includes DFI thermocouple data, SILTS data, and the temperature profile predicted by LAURA. The SILTS data for these plots was extracted from the image data shown in Fig. 11. The extracted SILTS data had to be stretched to properly register the leading and trailing edges. This is due to uncertainties in the optical transformations used to obtain the planform image as discussed in Ref. 37. In addition, the reader is cautioned that the aft portion of the LAURA solutions are not physical since the wing was not modeled accurately beyond the elevon hinge-line.

The forty percent semi-span station (Fig. 12a) shows that both sets of flight data show lower temperatures than the LAURA prediction. This might be due to conduction along the RCC leading edge which was not computationally modeled. At the sixty percent semispan station (Fig. 12b) the temperatures predicted by LAURA and the flight measurements are in very good agreement considering this semi-span station is very near the wing-bow shock interaction zone. The DFI thermocouple near the leading edge $(\mathrm{X} / \mathrm{C}=0.15)$, however, is considerably lower than either SILTS or LAURA. At the seventy-five percent semi-span station (Fig. 12c) the LAURA predictions are within five percent of both sets of flight data.

\section{Surface Heating}

Figure 13 shows heating comparisons for the windward and leeward centerlines. The windward centerline values are in very good agreement with all three DFI flights. One isolated discrepancy occurs at the fifteen percent fuselage station $(\mathrm{X} / \mathrm{L}=0.15)$ where the heating rates shown by the DFI data are non-monotonic for a short stretch of the vehicle surface. This is attributed to an acoustic microphone which melted on one of the first flights and contaminated a localized downstream area. It should be noted that several of the tiles on all flights (particularly STS-5) had catalytically enhanced surfaces. ${ }^{39}$ However, as discussed in Ref. 39, the area of influence appears to be very localized high heating rates. (These offending points have been omitted for the sake of clarity.) The predicted leeward centerline heating rates show a consistently lower trend than the measured flight 


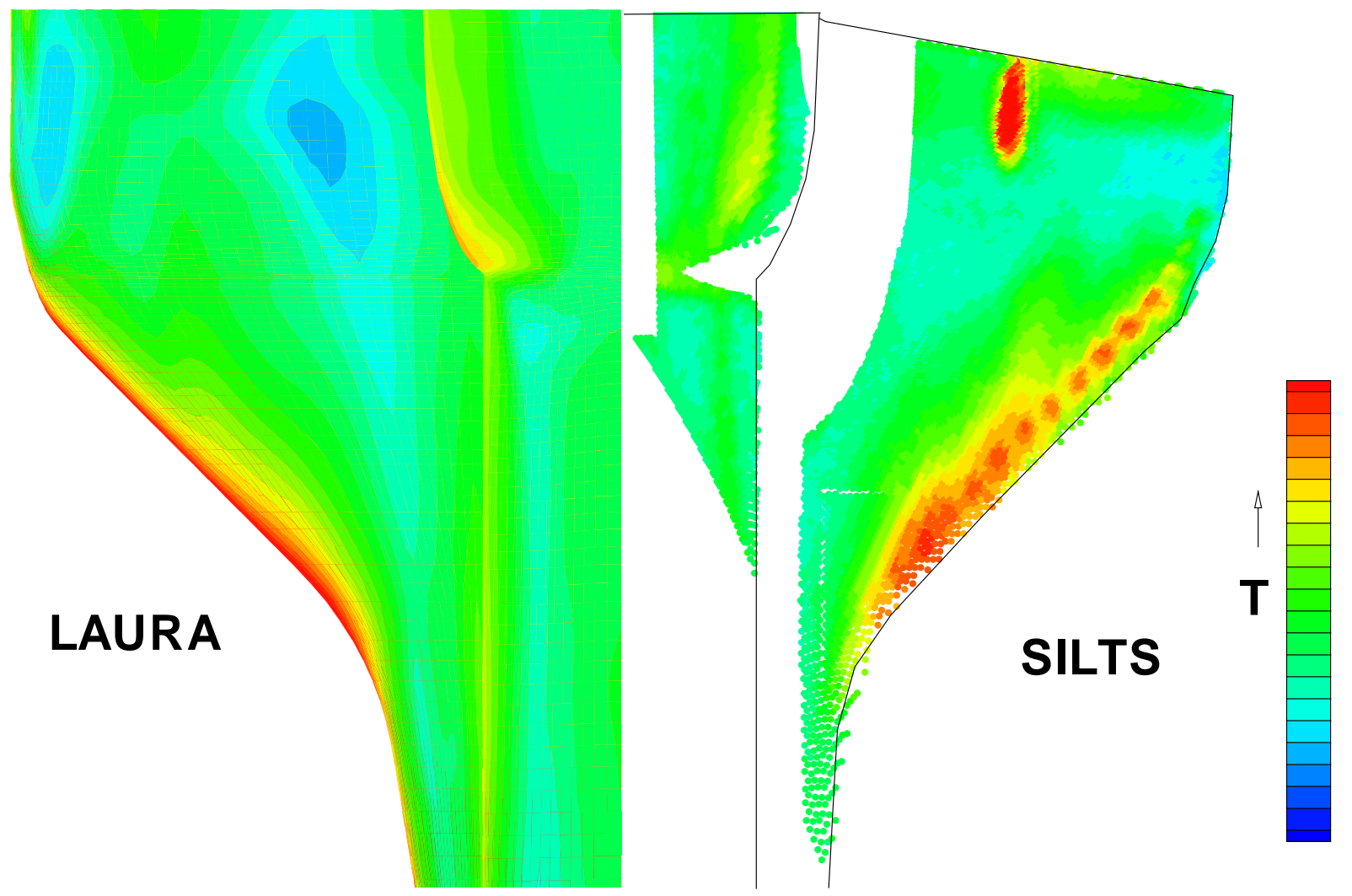

Figure 11: Leeside wall temperature comparison for the aft end of the Shuttle Orbiter.

data, and once past $\mathrm{X} / \mathrm{L}=0.55$ not even the trend in heating is captured correctly. Of particular note is the peak heating caused by the canopy shock is predicted significantly lower than that measured by flight data. This region is just aft of a bank of four Reaction Control System (RCS) jets which were not modeled. This region also contains the recessed windows and their associated gap seals, etc-none of which are modeled in detail. The low predicted heating in this area is of concern because the vortex which originates from just ahead of the canopy deposits its flow along the aft end of the fuselage (refer to Fig. 7). Since there are not very many grid points in the vicinity of this region (Fig. 3), the flow is not adequately resolved, and as a consequence of this vortical structure, the flow which later impinges on the aft end of the fuselage does not have as high of energy as it should. Another plausible factor contributing to the lower predicted heating rates is the solar radiation present at this altitude. Throckmorton ${ }^{40}$ shows that solar radiation contribution to the heating rates on isolated leeside gauges could be up to 60 percent of the total for a given inclination to the Sun during reentry.

The heating comparisons at several fuselage cross- section stations are shown in Figure 14. As with the pressures, the meridional angle, $\Phi$, is measured from the leeward symmetry plane around to the windward symmetry plane, and each figure includes a half-section depiction of the fuselage at the particular station.

Figure 14a shows the first fuselage station $(\mathrm{X} / \mathrm{L}=0.1)$. This station is located midway between the cluster of four RCS jets and the beginning of the canopy. The predicted, leeward heating rates are somewhat lower than the measured flight data. However, as one approaches the windward surfaces the predicted heating rates show excellent agreement with the flight data.

Figure $14 \mathrm{~b}$ represents the $\mathrm{X} / \mathrm{L}=0.25$ fuselage station which is located just aft of the forward facing windows, but still encompasses the swept-back portion of the fuselage which accommodates the side-facing windows. This station shows a trend similar to the previous station: under-prediction when nearing the leeward centerline, but excellent agreement on the sidewall and windward surfaces. At this station, however, the trend of near the leeside centerline is not even captured.

Figure $14 \mathrm{c}(\mathrm{X} / \mathrm{L}=0.3)$ is located just aft of the previous station, and no longer encompasses the swept-back 


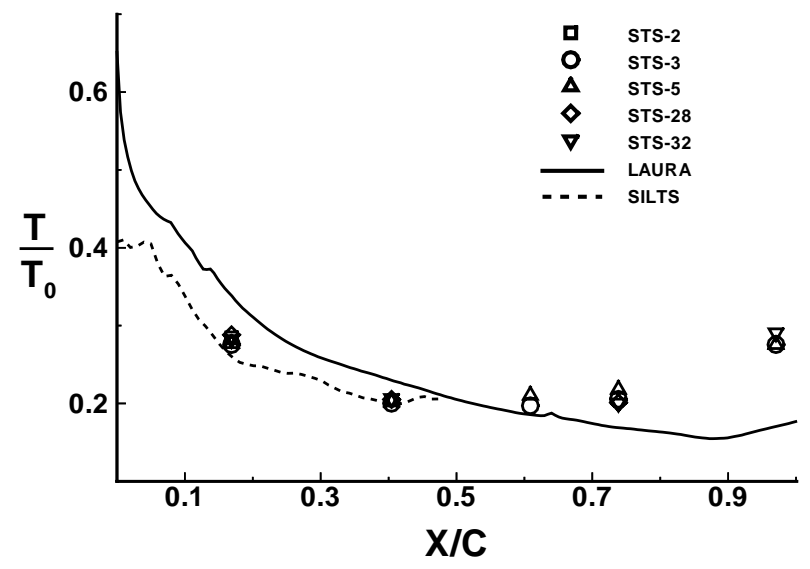

(a) Wing station $2 \mathrm{Y} / \mathrm{B}=0.40$.

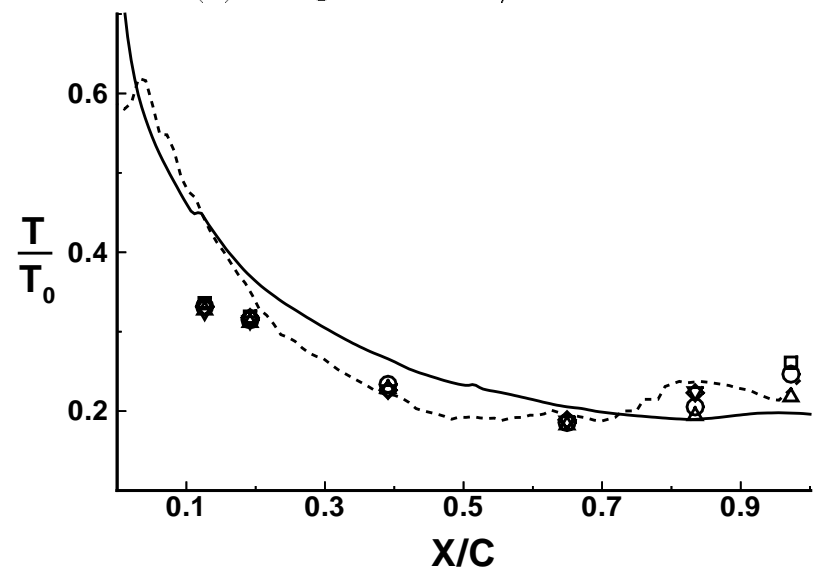

(b) Wing station $2 \mathrm{Y} / \mathrm{B}=0.60$.

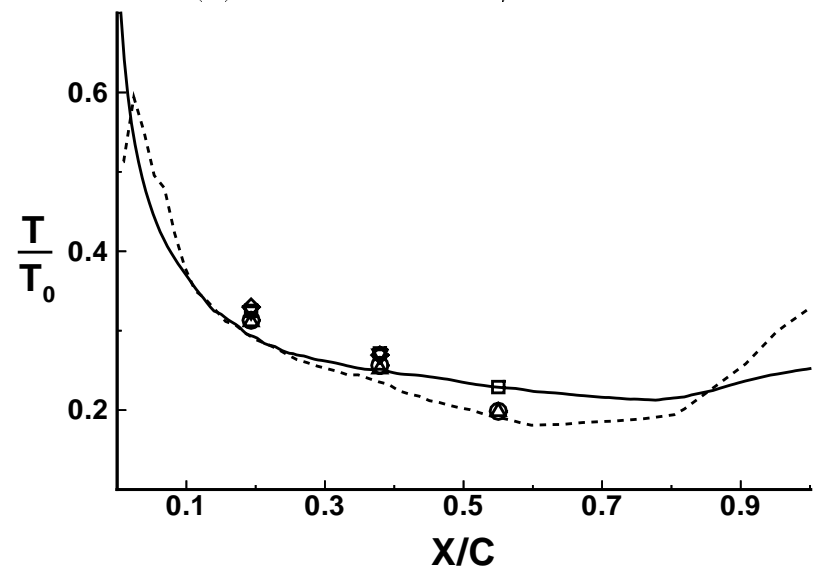

(c) Wing station $2 \mathrm{Y} / \mathrm{B}=0.75$.

Figure 12: Temperature distribution comparisons at various wing semi-span stations as a function of chord.

portion of the fuselage due to the side facing windows. Once again, the windward heating rates agree well, while the predicted leeside heating rates are lower than those measured in flight. Again, the trend of the heating rates

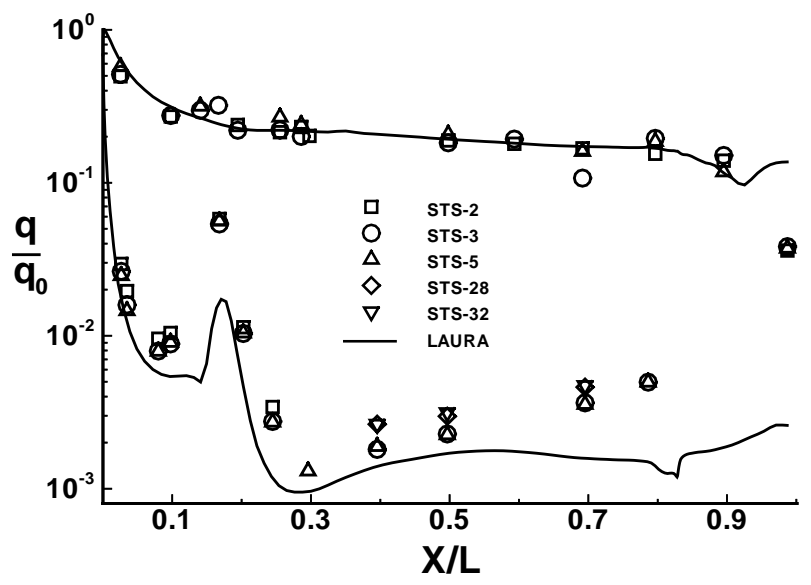

Figure 13: Windward and leeward centerline heating rate comparisons.

near the leeside centerline is not properly captured.

Figure 14d depicts the fuselage station at $\mathrm{X} / \mathrm{L}=0.4$. At this point, both the windward and leeward heating predictions agree very well with the measured flight data. The predicted heating near the leeside centerline is still slightly lower than the flight data, but the proper trend is now evident.

The next fuselage station $(\mathrm{X} / \mathrm{L}=0.5)$ is shown by Fig. 14e. As with the previous cross-sectional station, the leeside heating rates are in slight disagreement, but all the trends are captured. A slight disparity in the flight data is noted at a $\Phi$ of approximately $75^{\circ}$.

The next three sub-figures: $14 \mathrm{f}, 14 \mathrm{~g}$, and $14 \mathrm{~h}$ show the computed and measured heating rates for fuselage stations of $\mathrm{X} / \mathrm{L}=0.6,0.7$, and 0.8 . All show similar trends: excellent agreement on the windward and side surfaces, but over-prediction of the heating rates on the upper surface of the wing and under-prediction on the lee surface of the fuselage.

\section{General Observations}

As a check of the thin-layer Navier-Stokes assumption, the neglected viscous terms are added in two stages. The first stage is the addition of the circumferential component. The inclusion of this term involves no additional memory and is relatively inexpensive to compute. With this additional term, the changes in the heating rates are highly localized and generally less than five percent. These occur in the wing/bow-shock interaction region, in the vicinity of the wing-tip cross-flow shock, and just ahead of the OMS pods. The second stage is to use the full Navier-Stokes equations. This increases the code's memory requirement by approximately fifteen percent, but the computational overhead is no more than five percent. Although the arguments of Baldwin et al. ${ }^{27}$ 


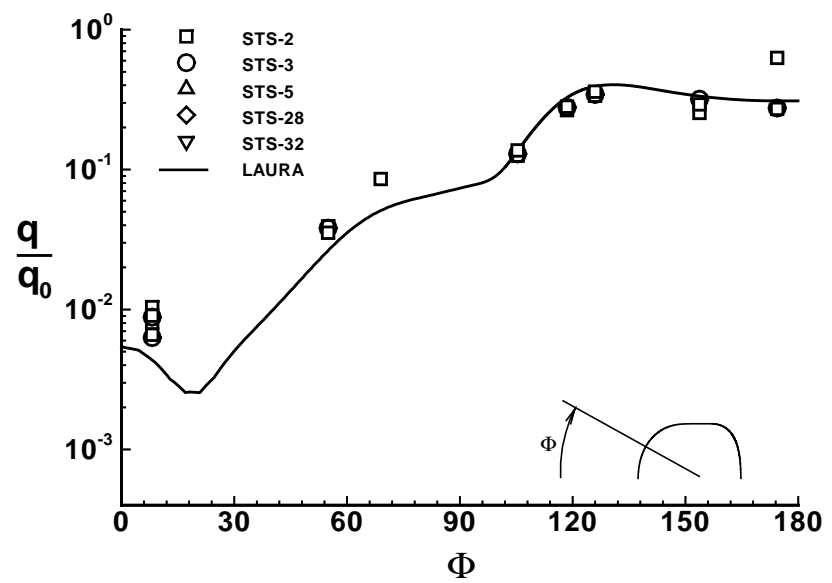

(a) Fuselage station $\mathrm{X} / \mathrm{L}=0.10$.

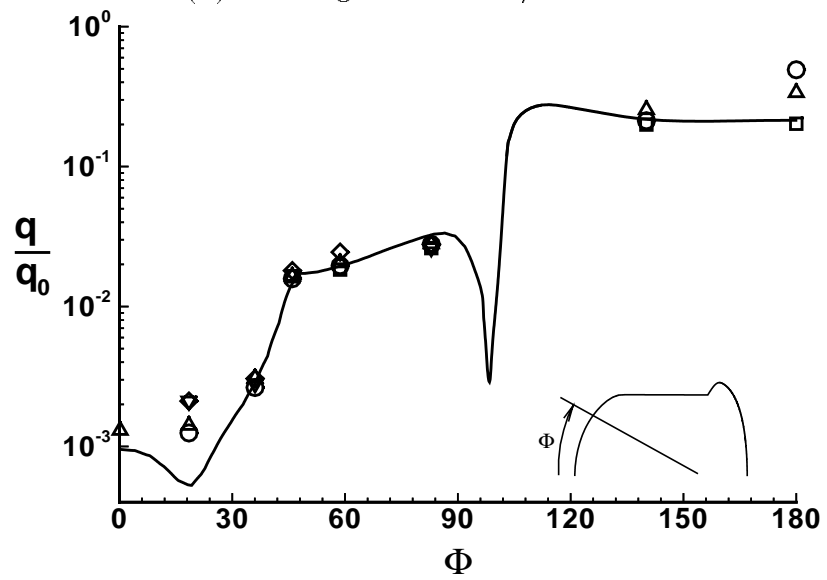

(c) Fuselage station $\mathrm{X} / \mathrm{L}=0.30$.

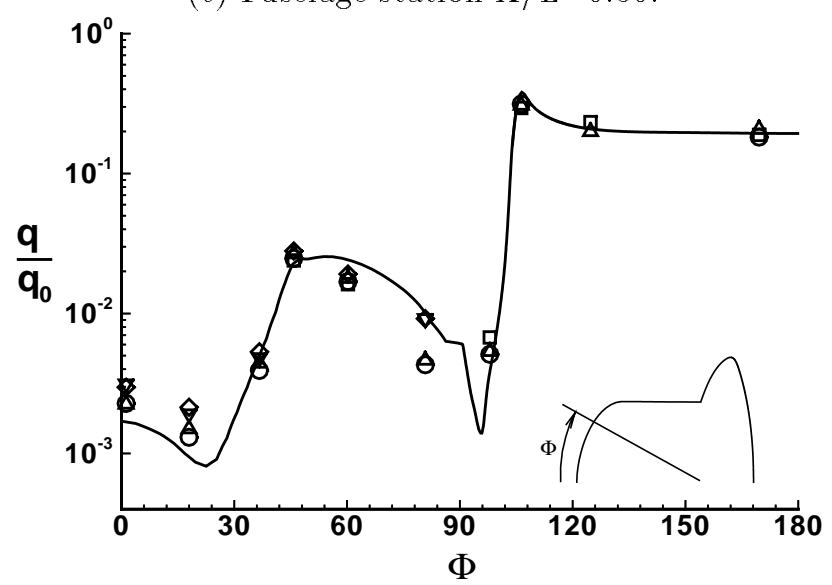

(e) Fuselage station $\mathrm{X} / \mathrm{L}=0.50$.

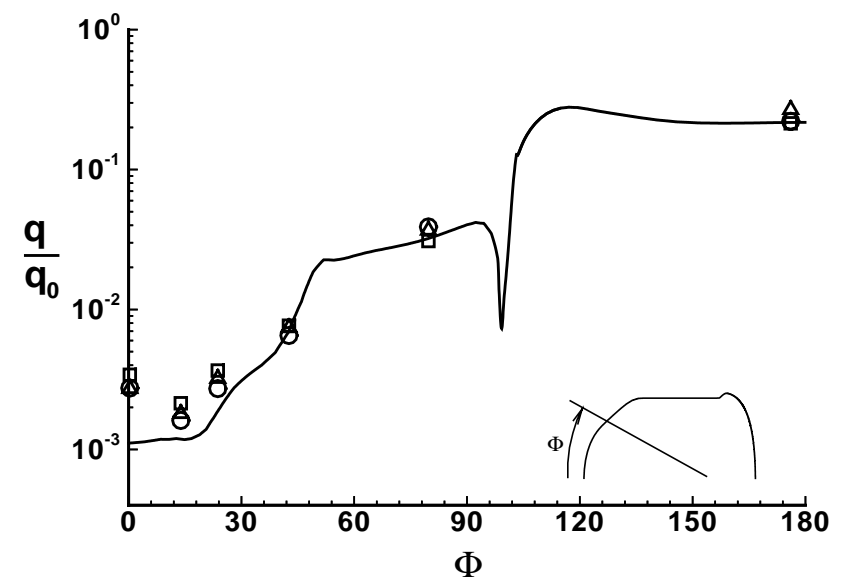

(b) Fuselage station $\mathrm{X} / \mathrm{L}=0.25$.

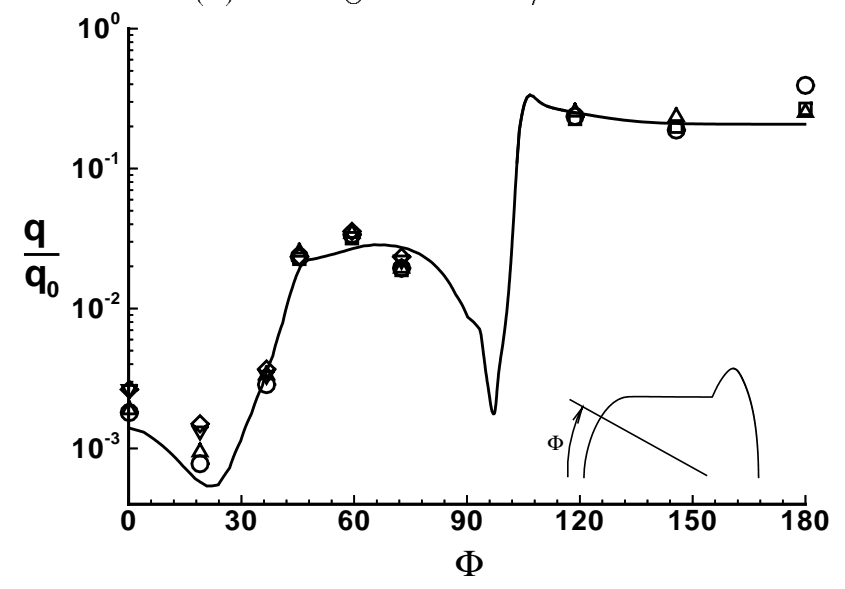

(d) Fuselage station $\mathrm{X} / \mathrm{L}=0.40$.

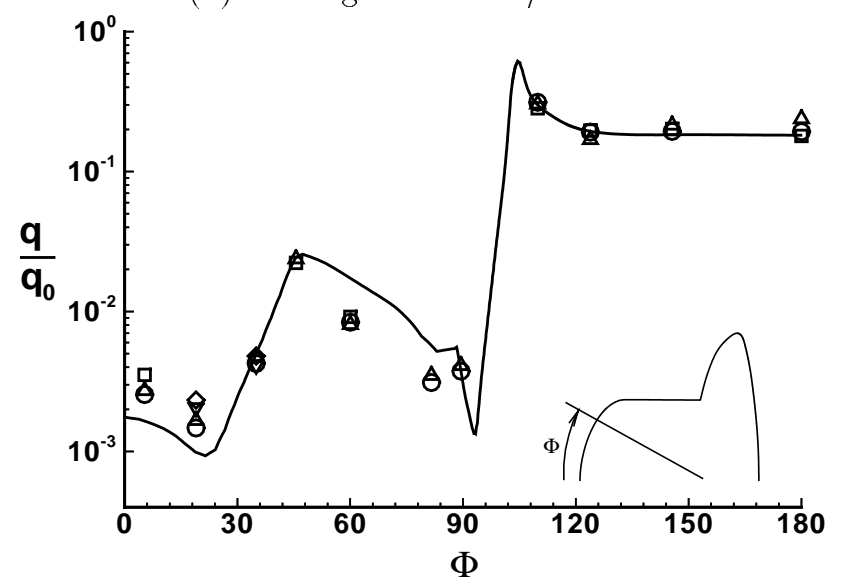

(f) Fuselage station $\mathrm{X} / \mathrm{L}=0.60$.

Figure 14: Cross-sectional heating comparisons at various fuselage stations along the vehicle. 


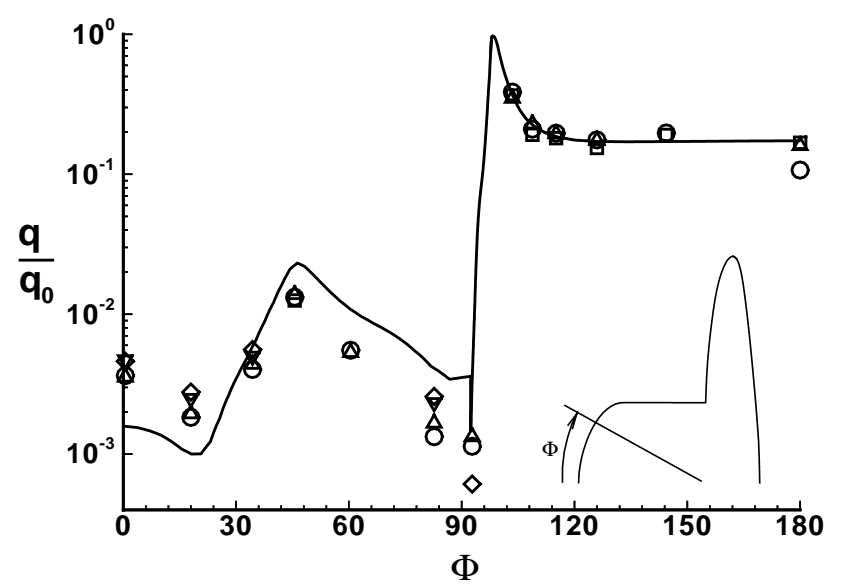

(g) Fuselage station $\mathrm{X} / \mathrm{L}=0.70$.

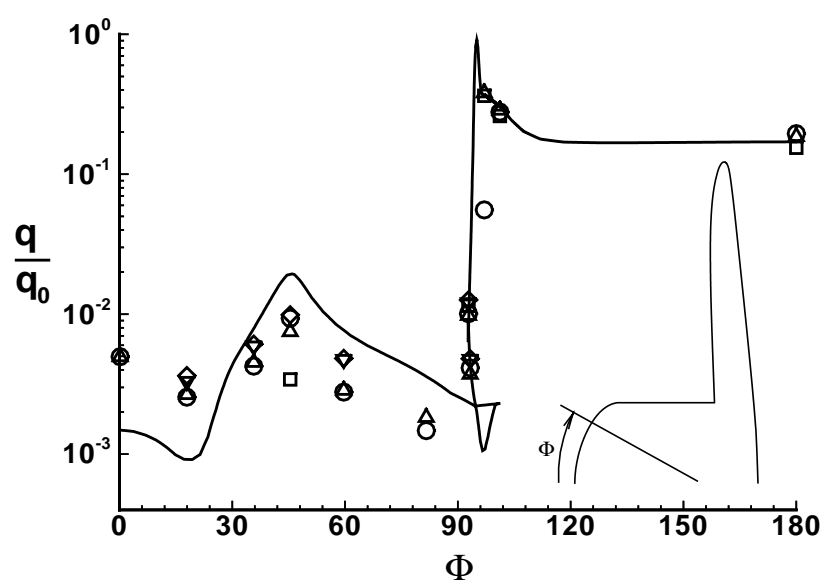

(h) Fuselage station $\mathrm{X} / \mathrm{L}=0.80$.

Figure 14: Concluded.

indicate that, in general, the effects of the additional terms would be negligible, results demonstrate that in confined regions, the leeside heating rates change by as much as thirty percent. For example the heating rates on the sidewall of the fuselage in the region below the shear-line extending between the start of wing-strake (refer to Fig. 6) decrease significantly. This is as might be expected since this is a highly vortical region of the flow. The heating increases by twenty percent along both cross-flow shocks on the wing. Also, a decrease in heating is noted at the front of the OMS pods and along the lower OMS pods/fuselage juncture.

The procedures used to calculate the heating rates from the DFI data ${ }^{17-19}$ make assumptions concerning the integrity of the thermocouple/thermal protection material joint. For the flexible materials used throughout the leeside of the Shuttle Orbiter, this is not necessarily a valid assumption. Estimates of error in the procedures outlined in Refs. 17-19 do not include the errors present in the thermocouple measurements themselves. Therefore, considerable unknowns are present in the thermocouple flight data and corresponding heat transfer rates.

The atomic recombination coefficients (i.e., wall catalysis) for the surfaces of the Shuttle Orbiter are very difficult to measure precisely. This is evident in the wide spread of atomic rate coefficients determined experimentally for only one type of surface coating material in a limited temperature range. ${ }^{41}$ As mentioned earlier, all the surfaces of the Shuttle Orbiter were modeled as having the same catalycity function with temperature. This is definitely not the case because there are many different types of surface coatings. For example, the Advanced Flexible Reusable Surface Insulation (AFRSI) which is used in many regions on the the leeside of the Orbiter is not coated with the same RCG coating that the catalycity model considers. This global model is also not correct for the RCC found on the wing leading edges and the fuselage nose cone. Other factors such as surface aging and contamination are completely unknown, but are expected to produce only second-order effects.

\section{Conclusions}

A computational solution was presented for a reentry condition of the Shuttle Orbiter at $40^{\circ}$ angle of attack for an altitude of $70 \mathrm{~km}$. The initial results demonstrate that the flow structure is quite complex, maintaining several vortical structures, separation lines, shock-shock interaction, and regions of low density, frozen flow.

The computed pressures agree well with flight data on the windward and leeward centerlines and for a fuselage cross-section. The pressures along a wing semispan station also show good agreement for the windside, but differ considerably on the leeside near the inboard/outboard elevon gap which was not modeled computationally.

The temperature distributions on the leeside of the wing are well predicted by LAURA. The wing-bow shock interaction region is evident as well as the peak heating on the wing leading edge. This offers confidence in accurately predicting the leeside thermal environment for design considerations.

Using the thin-layer Navier-Stokes assumption for the leeside flow appears to be adequate for the flight condition studied in this paper. The effects of adding the remaining viscous terms produced only localized changes in the heating rates for the leeside flow, and had absolutely no effect on the windside of the vehicle. Of course 
a grid refinement study is necessary to completely answer this question.

The heating rates, overall, compare very favorably with those measured by DFI flight data. The heating rates predicted by LAURA for the top of the aft fuselage are considerably lower than that measured by DFI data. It is expected that better resolution of a vortical structure emanating from the canopy region might rectify this.

\section{Acknowledgments}

The authors would like to thank Fred Martin of Johnson Space Center, Houston, Texas, and Samir Despande of AMD, Hampton, Virginia, for the databases used to create the final surface meshes, and Steven Alter of Lockheed, Hampton, Virginia, for aiding in the creation of the initial surface and volume grids used for the computation. The authors would also like to thank Dr. Peter Gnoffo for his bounty of helpful strategies for running LAURA and Dr. Lin Hartung for her help in extracting the pressure and heating data from the archaic Shuttle data tapes.

\section{References}

${ }^{1}$ P. Kutler, W. A. Reinhardt, and R. F. Warming, "Multishocked, Three-Dimensional Supersonic Flowfields with Real Gas Effects," AIAA Journal, vol. 11, pp. 657-664, May 1973. (See also AIAA Paper 72-702.).

${ }^{2}$ F. Marconi, M. Salas, and L. Yaeger, "Development of a Computer Code for Calculating the Steady Super/Hypersonic Inviscid Flow Around Real Configurations," NASA CR 2675, 1976.

${ }^{3}$ L. B. Schiff and J. L. Steger, "Numerical Simulation of Steady Supersonic Viscous Flow," NASA TP 1749, May 1981. (See also AIAA Paper 79-0130, January 1979.).

${ }^{4}$ C. P. Li, "Numerical Simulation of Reentry Flow Around the Shuttle Orbiter Including Real Gas Effects," Computers in Flow Predictions and Fluid Dynamics Experiments, pp. 141-145, November 1981.

${ }^{5}$ C. P. Li, "Implicit Solution for the Shock-Layer Flow around General Bodies," AIAA Journal, vol. 20, pp. 175-183, February 1982. (See also AIAA Paper 810191.).

${ }^{6}$ E. Venkatapathy, J. V. Rakich, and J. C. Tannehill, "Numerical Solution of Space Shuttle Orbiter Flow Field," AIAA Paper 82-0028, January 1982.

${ }^{7}$ A. Balakrishnan, "Computation of a Viscous Real Gas Flowfield for the Space Shuttle Orbiter," AIAA Paper 84-1748, June 1984.

${ }^{8}$ D. K. Prabhu and J. C. Tannehill, "Numerical Solu- tion of Space Shuttle Orbiter Flow Field Including Real Gas Effects," AIAA Paper 84-1747, June 1984.

${ }^{9}$ K. J. Weilmuenster, "High Angle of Attack Inviscid Flow Calculations Over a Shuttle-like Vehicle with Comparisons to Flight Data," AIAA Paper 83-1798, 1983.

${ }^{10}$ K. Y. Szema, B. J. Griffith, J. R. Maus, and J. T. Best, "Laminar Viscous Flow Field Prediction of Shuttle-Like Vehicle Aerodynamics," AIAA Paper 830211, January 1983.

${ }^{11}$ J. R. Maus, B. J. Griffith, K. Y. Szema, and J. T. Best, "Hypersonic Mach Number and Real Gas Effects of Space Shuttle Orbiter Aerodynamics," AIAA Paper 83-0343, January 1983.

${ }^{12}$ A. Balakrishnan, C. K. Lombard, and W. C. Davy, "Real Gas Flowfields About Three Dimensional Configurations," AIAA Paper 83-0581, January 1983.

${ }^{13}$ B. Stoufflet, J. Periaux, F. Fezoui, and A. Dervieux, "Numerical Simulation of 3-D Hypersonic Euler Flows Around Space Vehicles Using Adapted Finite Elements," AIAA Paper 87-0560, January 1987.

${ }^{14}$ Y. Wada and H. Kubota, "Numerical Simulation of Re-Entry Flow around the Space Shuttle with FiniteRate Chemistry," in Proceedings of the Seventeenth International Symposium on Space Technology and Science, May 1990.

${ }^{15}$ Y. Wada, S. Ogawa, H. Kubota, and T. Akimoto, "Numerical Simulation of Re-Entry Flow around the Space Shuttle with Finite-Rate Chemistry," in Proceedings of the Seventeenth International Symposium on Space Technology and Science, pp. 719-728, May 1990.

${ }^{16}$ Y. Yamamoto, "Numerical Simulation of Hypersonic Viscous Flow for the Design of H-II Orbiting Plane (HOPE): Part II," AIAA Paper 91-1390, June 1991.

${ }^{17} \mathrm{~L}$. C. Hartung and D. A. Throckmorton, "Space Shuttle Entry Heating Data Book: Vol I-STS-2," NASA RP 1191, May 1988.

${ }^{18}$ L. C. Hartung and D. A. Throckmorton, "Space Shuttle Entry Heating Data Book: Vol II-STS-3," NASA RP 1192, May 1988.

${ }^{19}$ L. C. Hartung and D. A. Throckmorton, "Space Shuttle Entry Heating Data Book: Vol III-STS-5," NASA RP 1193, May 1988.

${ }^{20}$ D. A. Throckmorton, E. V. Zoby, and A. G. Kantsios, "The Shuttle Infrared Leeside Temperature Sensing (SILTS) Experiment," AIAA Paper 85-0328, January 1985.

${ }^{21}$ J. P. Steinbrenner, J. R. Chawner, and C. L. Fouts, "The GRIDGEN 3D Multiple Block Grid Generation System: Volume I-Final Report," WRDC TR 90-3022, July 1990.

${ }^{22}$ P. L. Roe, "Approximate Riemann Solvers, Parameter Vectors, and Difference Schemes," Journal of Computational Physics, vol. 43, pp. 357-372, October 1981. 
${ }^{23}$ H. C. Yee, "On Symmetric and Upwind TVD Schemes," NASA TM 88325, 1986.

${ }^{24}$ A. Harten, "High Resolution Schemes for Hyperbolic Conservation Laws," Journal of Computational Physics, vol. 49, pp. 357-393, February 1983.

${ }^{25}$ P. A. Gnoffo, “An Upwind-Biased, Point-Implicit Relaxation Algorithm for Viscous, Compressible PerfectGas Flows," NASA TP 2953, February 1990.

${ }^{26}$ L. C. Hartung and D. A. Throckmorton, "Computer Graphic Visualization of Orbiter Lower Surface Boundary-Layer Transition," Journal of Spacecraft and Rockets, vol. 24, pp. 109-114, March-April 1987.

${ }^{27}$ B. S. Baldwin and H. Lomax, "Thin Layer Approximation and Algebraic Model for Separated Turbulent Flows," AIAA Paper 78-257, January 1978.

${ }^{28}$ P. A. Gnoffo, R. N. Gupta, and J. Shinn, "Conservation Equations and Physical Models for Hypersonic Air Flows in Thermal and Chemical Nonequilibrium," NASA TP 2867, 1989.

${ }^{29}$ C. Park, "Assessment of Two-Temperature Kinetic Model for Ionizing Air," AIAA Paper 87-1574, June 1987.

${ }^{30} \mathrm{C}$. Park, Nonequilibrium Hypersonic Aerothermodynamics. John Wiley \& Sons, Inc., 1990.

${ }^{31}$ L. C. Hartung and H. A. Hassan, "Radiation Transport Around Axisymmetric Blunt Body Vehicles Using a Modified Differential Approximation," AIAA Paper 920119, January 1992.

${ }^{32}$ E. V. Zoby, R. N. Gupta, and A. L. Simmonds, "Temperature-Dependent Reaction-Rate Expression for Oxygen Recombination at Shuttle Entry Conditions," AIA A Paper 84-0224, January 1984.

${ }^{33}$ C. D. Scott, "Catalytic Recombination of Nitrogen and Oxygen on High-Temperature Reusable Surface Insulation," AIAA Paper 80-1477, 1980.

${ }^{34}$ Y. C. Kim, "Study of the Recombination of Nitrogen and Oxygen Atoms on Surfaces of Materials Used in Space Vehicles: Final Report," NCA 2-158, Stanford University, September 1986.

${ }^{35}$ W. J. Marinelli and J. P. Campbell, "SpacecraftMetastable Energy Transfer Studies: Final Report," NAS 9-17565, July 1986.

${ }^{36}$ W. J. Marinelli, "Collisional Quenching of Atoms and Molecules on Spacecraft Thermal Protection Surfaces," AIAA Paper 88-2667, June 1988.

${ }^{37}$ D. A. Throckmorton, J. C. Dunavant, and D. L. Myrick, "Shuttle Infrared Leeside Temperature Sensing (SILTS) Experiment-STS 28 Preliminary Results," AIAA Paper 90-1741, June 1990.

${ }^{38}$ K. J. Weilmuenster and P. A. Gnoffo, "Solution Strategies and Heat Transfer Calculations for ThreeDimensional Configurations at Hypersonic Speeds," AIAA Paper 92-2921, July 1992.
${ }^{39}$ D. A. Stewart, J. V. Rakich, and M. J. Lanfranco, "Catalytic Surface Effects Experiment on Space Shuttle," AIA A Paper 81-1143, June 1981.

${ }^{40}$ D. A. Throckmorton, "Influence of Radiant Energy Exchange on the Determination of Convective HeatTransfer Rates to Orbiter Leeside Surfaces during Entry," in Entry Vehicle Heating and Thermal Protection Systems: Space Shuttle, Solar Starprobe, Galileo Probe (P. E. Bauer and H. E. Collicott, eds.), vol. 85 of Progress in Astronautics and Aeronautics, pp. 78-96, AIAA, 1983. (See also AIAA Paper 82-0824.).

${ }^{41}$ D. A. Stewart, Y.-K. Chen, and W. D. Henline, "Effect of Non-Equilibrium Flow Chemistry and Surface Catalysis on Surface Heating to AFE," AIAA Paper 911373, June 1991. 